\title{
Optically stimulated luminescence dating of sandy deposits from Gulang county at the southern margin of the Tengger Desert, China
}

\author{
PENG Jun ${ }^{1 *}$, DONG Zhibao ${ }^{1}$, HAN Fengqing ${ }^{2}$ \\ ${ }^{1}$ Key Laboratory of Desert and Desertification, Cold and Arid Regions Environmental and Engineering Research Institute, \\ Chinese Academy of Sciences, Lanzhou 730000, China; \\ ${ }^{2}$ Qinghai Institute of Salt Lakes, Chinese Academy of Sciences, Xining 810008, China
}

\begin{abstract}
Aeolian deposits from the deserts in northern China have been used for palaeoenvironmental research to understand aeolian sedimentology and its dynamic connection to past climate conditions. The Tengger Desert in China is sensitive to the waxing and waning of the monsoonal system. In response to past climate change, the southern margin of the Tengger Desert has evolved significantly since the last glacial period. However, previous attempts to date aeolian deposits in this region were mainly based on radiocarbon dating, which has problems when applied to aeolian deposits. Moreover, sedimentary records are limited. Accordingly, past aeolian activity in this desert remains poorly understood. In the present study, we dated sand samples from Gulang county at the southern margin of the Tengger Desert using optically stimulated luminescence (OSL) to understand the history of aeolian activity in this region. Our samples represented well-sorted aeolian sands and sandy loess. Aeolian sands are evidence of dune field buildup and sparse vegetation cover whereas sandy loess is evidence of improved stabilization of sand dunes resulting from ameliorated vegetation cover. Certain samples showed a decline in the equivalent dose $\left(D_{e}\right)$ values when successive integration intervals were applied, which resulted from unstable OSL signals from non-fast components in the initial part of the decay curve. In order to obtain reliable $D_{e}$ estimates, we investigated component-resolved and different background subtraction approaches, and compared the resultant $D_{e}$ estimates. We adopted the early background subtraction method to derive $D_{e}$ values. Luminescence chronologies and sedimentary records indicated that sand dunes accumulation occurred before $10 \mathrm{ka}$, and sandy loess developed between 9.5 and $7.6 \mathrm{ka}$ when sand dunes were stabilized as a result of increased effective moisture levels. The transition between sand dune mobilization and stabilization emphasizes the significance of an effective moisture threshold in controlling aeolian activity. Mobilization of sand dunes at $\sim 2.3 \mathrm{ka}$ might be related to an increased aridity during the Late Holocene.
\end{abstract}

Keywords: OSL dating; sandy deposit; integration interval selection; aeolian activity; Tengger Desert

Citation: PENG Jun, DONG Zhibao, HAN Fengqing. 2016. Optically stimulated luminescence dating of sandy deposits from Gulang county at the southern margin of the Tengger Desert, China. Journal of Arid Land, 8(1): 1-12. doi: $10.1007 / \mathrm{s} 40333-015-0137-6$

Aeolian sediments are the main deposit type in arid and semiarid regions. Although they support minimal biogenic activity and sparse vegetation cover, they are important for understanding aeolian sedimentary and geomorphological process as well as their dynamic responses to past climate variation. Fixed and semi-fixed sand dunes cover a large area in northern China. They are

${ }^{*}$ Corresponding author: PENG Jun (E-mail: pengjun10@mails.ucas.ac.cn)
Received 2015-01-20; revised 2015-03-24; accepted 2015-07-01
(C) Xinjiang Institute of Ecology and Geography, Chinese Academy of Sciences, Science Press and Springer-Verlag Berlin Heidelberg 2016 
sensitive to external forcing factors such as temperature, wind strength, and precipitation. A number of studies showed that the southern borders of the deserts in northern China shifted substantially in time and space in response to variations in East Asian monsoon intensity (Li and Sun, 2006; Feng et al., 2013; Lu et al., 2013). Thus, these deserts provide a critical region for palaeoclimatic research. Alternations in sandy soil and loess development and in sand dune accumulation are recognized as evidence of desert retreat and expansion ( $\mathrm{Li}$ and Sun, 2006). Aeolian sand is an indication of dune field buildup as well as a proxy for episodic sand dune accumulation, whereas sandy soil or loess that contains a much higher content of fine-grained particles indicates more humid climate conditions and increased vegetation cover. Sedimentary records from these archives provide useful information to understand past climate conditions.

The Tengger Desert is located in the loess-desert transitional zone southwest of Alxa Left Banner in the central part of Inner Mongolia autonomous region, near the Yellow River Basin in northern China (Sun et al., 2013). As the fourth largest desert in China, the Tengger Desert covers an area of about $36,000 \mathrm{~km}^{2}$. It is a tectonically derived alluvial plain of the Alashan plateau, with an elevation ranging from 1,000 to $1,500 \mathrm{~m}$ asl. It is a fault basin bounded by the Qilian Mountains in the southwest, Yabulai Mountains in the west, and the Helan Mountains in the east. The sandy desert basin is covered by fixed dunes, basement outcrops, and mountain ridges composed of Precambrian and Paleozoic metamorphic and crystalline rocks (Pachur et al., 1995). The southern margin of the Tengger Desert stretches eastward as far as into the transition zone between the desert and the Loess Plateau. The physiographic settings of the study region suggest that sedimentary records in this region should respond sensitively to changes in regional climate conditions.

Previous absolute dating of sandy deposits around the Tengger Desert was mainly based on radiocarbon dating or thermoluminescence (TL) dating, and only limited age points were used as chronological controls. Researches on palaeoclimatic reconstructions are limited for radiocarbon-dated aeolian deposits in this region (Qiang et al., 2000; Gao et al., 2001; Li et al., 2006). Moreover, problems exits when radiocarbon dating is used for dry-land materials due to calibration problems, contamination from modern and old carbon sources, and the open dating system (Singhvi and Porat, 2008). In contrast, the optically stimulated luminescence (OSL) dating technique determines the elapsed time since the last instance of exposure to sunlight or the last time that deposition occurred. It therefore provides a direct way of dating aeolian sediments. OSL methods have revolutionized palaeoclimatic research in desert regions and have been applied widely in dating sandy deposits from dune fields in northern China (Li et al., 2002, 2007; Li and Sun, 2006; Sun et al., 2006; Yang et al., 2010; Liu et al., 2012; Long et al., 2012; Yu and Lai, 2012; Zhao et al., 2012). More recently, OSL dating techniques have been used to date aeolian samples from the southern Tengger Desert (Qiang et al., 2010; Feng et al., 2013). As a result, limited high-quality chronological data are available, impeding our understanding of the history of aeolian activity in this region.

In the present study, we used OSL dating to develop chronologies for sandy deposits from Gulang county at the southern margin of the Tengger Desert. We identified episodes of changes in aeolian activity from the OSL ages and sedimentary records. Our results provide useful palaeoenvironmental information to support future research and to promote a better understanding of the correlations between climate change and aeolian processes in arid regions.

\section{Study area and methods}

\subsection{Study area}

The study area was located near Gulang county at the southern margin of the Tengger Desert (Fig. 1). Potential evaporation is approximately $2,292 \mathrm{~mm}$, versus a mean annual precipitation of only about $306 \mathrm{~mm}$. Rainfall in this area shows high seasonal variability, with $70 \%-80 \%$ occurring between July and September when the summer monsoon prevails. During winter and spring, the dominant wind direction is northwesterly ( $\mathrm{Lv}$ et al., 2009), and the wind causes frequent dust 
storms because of dry conditions at these times of year. Semi-fixed sand dunes covered by sparse vegetation are the present dominant landforms in the region.

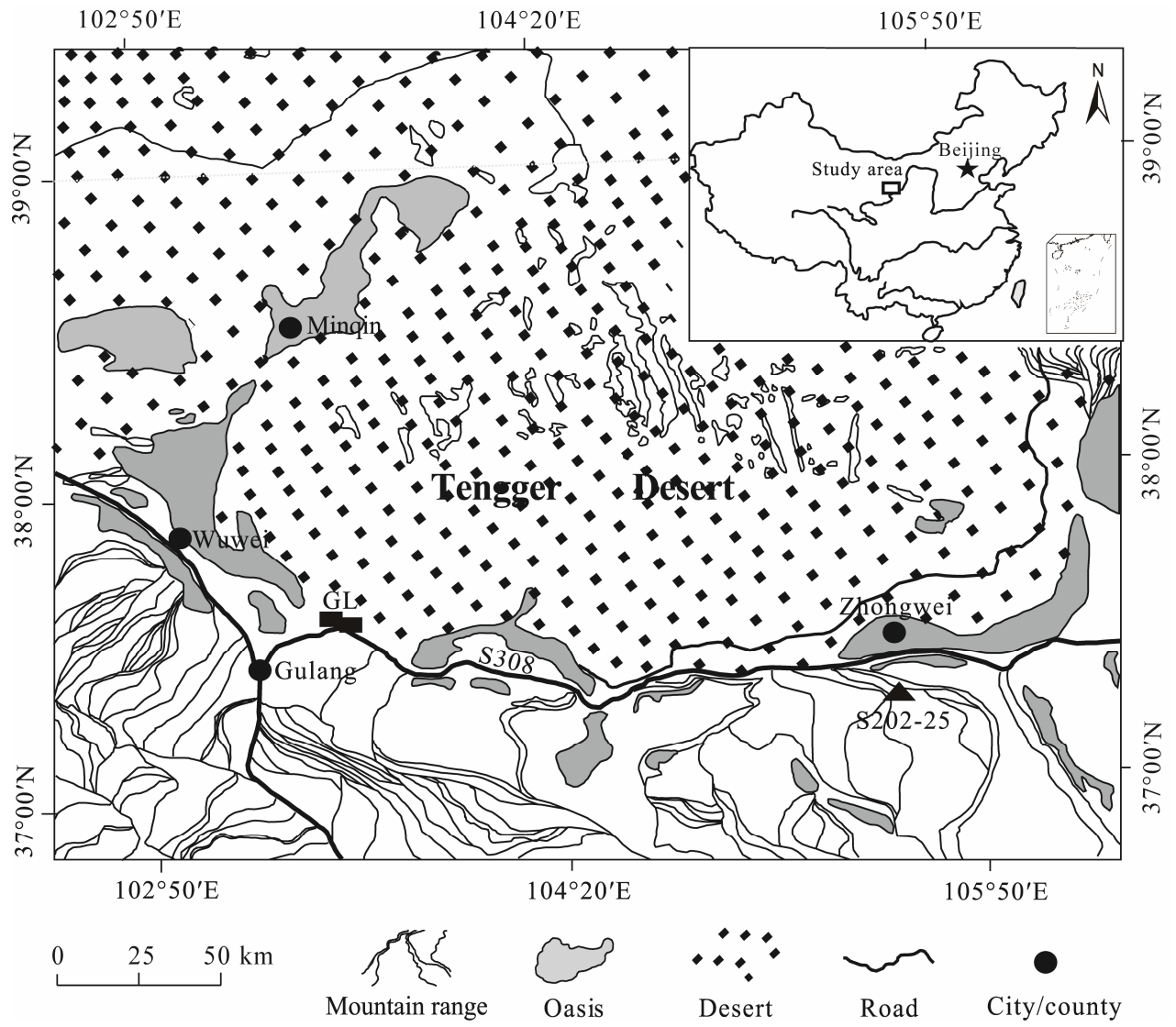

Fig. 1 Location of the study area. The rectangles denote the sampling sections (i.e. GL1 and GL2). The triangle indicates the location of a sedimentary sequence (i.e. S202-25) used for OSL dating in the southeastern Tengger Desert from previous studies (Feng et al., 2013; Lu et al., 2013; Sun et al., 2013).

\subsection{Sample preparation}

Samples were collected from two sections (i.e. GL1 and GL2; Fig. 1) near provincial road S308 for OSL dating. Aeolian sequences in this area consist mainly of alternating layers of sandy soils and aeolian sand deposits. Because the sedimentary sequences are quite thick, outcrops from the bottoms of sections do not denote the full depths of the sequences. We only used the upper parts of the deposits that could easily be sampled in our study. OSL samples were collected by hammering steel cylinders ( $25 \mathrm{~cm}$ long, $4 \mathrm{~cm}$ in diameter) into vertical outcrops.

We collected sediments from each end of the cylinder to measure the dose rate and water content in the laboratory. Raw samples were treated with $30 \% \mathrm{H}_{2} \mathrm{O}_{2}$ to remove organic materials and $10 \% \mathrm{HCl}$ to remove carbonates. We obtained particles in grain size fractions between 90 and $180 \mu \mathrm{m}$ in diameter via the wet sieving approach. The separated grain samples were then treated with $40 \% \mathrm{HF}$ for $2 \mathrm{~h}$ to etch feldspars contained in the grains. Finally, samples were treated with $10 \% \mathrm{HCl}$ to remove fluorides that precipitated during the etching process. We monitored the purity of the resultant quartz grains using infrared light stimulation with a wavelength of $830 \mathrm{~nm}$ to ensure that the remaining feldspar signals were effectively removed (Lai and Brückner, 2008). For measurement purposes, we mounted quartz grains in the center part ( 5 to $6 \mathrm{~mm}$ ) of a $10-\mathrm{mm}$ diameter stainless steel disc coated in silicone oil.

\subsection{OSL measurements}

We carried out continuous-wave (CW) OSL measurements using an automated Risø TL/OSL 
DA-20 reader. Decay signals were obtained by stimulating quartz grains under a blue LED source with a wavelength of $470 \mathrm{~nm}$ at $130^{\circ} \mathrm{C}$ for $40 \mathrm{~s}$ (at $90 \%$ of maximum laser power) using 250 equal-width channels. We used a 7.5-mm-thick U-340 filter to detect OSL signals, and adopted a ${ }^{90} \mathrm{Sr} /{ }^{90} \mathrm{Y}$ beta source with a dose rate of $0.13 \mathrm{~Gy} / \mathrm{s}$ to generate laboratory irradiation. Additionally, we employed the single-aliquot regenerative dose (SAR) approach (Murray and Wintle, 2000) to determine the equivalent dose $\left(D_{e}\right)$ values. We applied preheating temperatures ranging from $220^{\circ} \mathrm{C}$ to $300^{\circ} \mathrm{C}$ with an interval of $20^{\circ} \mathrm{C}$ to sample GL $2-1$ to determine the optimal preheating conditions that would minimize thermal transfer effects. For this testing, we fixed the cut heat (thermal treatment) temperature at $220^{\circ} \mathrm{C}$ for $10 \mathrm{~s}$, and each temperature point was investigated using four aliquots. Figure 2 shows that for all tested temperature points, the recycling ratios were within $10 \%$ of unity (Fig. 2a) and the recuperation values were less than $10 \%$ (Fig. 2b). We further checked the suitability of the preheating conditions and the applicability of the SAR protocol by employing a dose-recovery test, in which grains were first bleached through laboratory stimulations and were then given a known artificial dose. The natural OSL signal was removed by optical stimulation under a blue LED source at $130^{\circ} \mathrm{C}$ for $40 \mathrm{~s}$. A laboratory dose of 26 Gy was then applied using the ${ }^{90} \mathrm{Sr} /{ }^{90} \mathrm{Y}$ beta source mounted on the reader, and we used the SAR protocol to measure the given dose value. We observed that for all the preheating temperature points, the ratios of the measured dose to the given dose were within $10 \%$ of unity (Fig. 2c). Based on the results in Fig. 2, we chose a preheating temperature of $260^{\circ} \mathrm{C}$ and a cut heat of $220^{\circ} \mathrm{C}$.
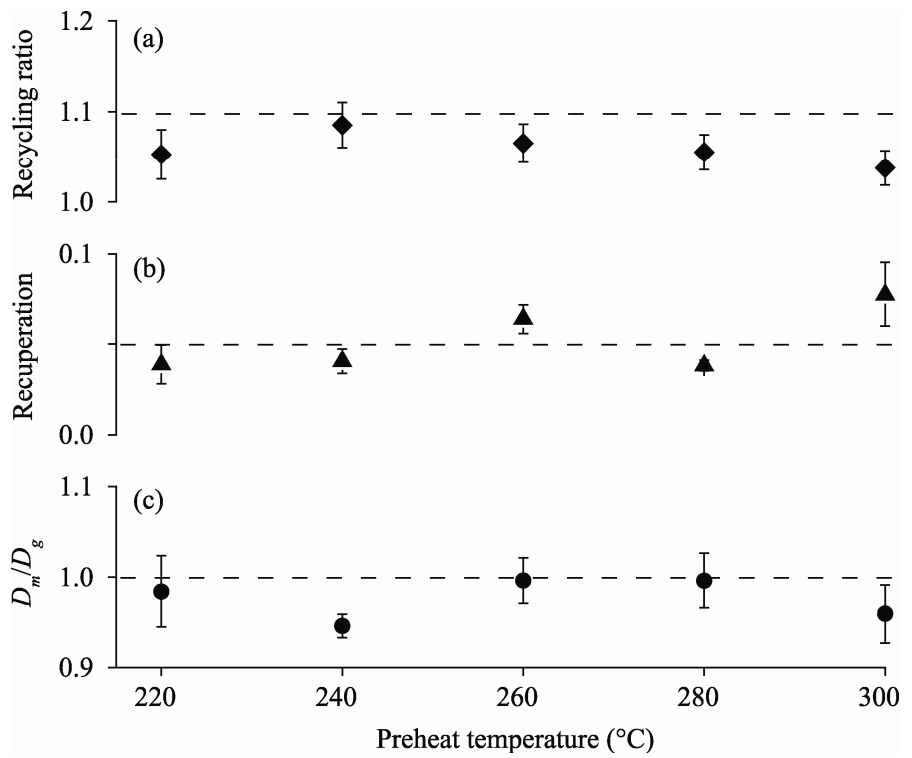

Fig. 2 Results from the preheating plateau and dose-recovery test for sample GL2-1. (a) the recycling ratio, (b) the recuperation, and (c) the ratio of the measured dose $\left(D_{m}\right)$ to given dose $\left(D_{g}\right)$ for each preheating temperature. Each data point is based on the mean value from four aliquots.

\section{Results and discussion}

\subsection{Effects of integration intervals on $D_{e}$}

The SAR protocol assumes that the initial part of the decay signal is dominated by the fast component, and thus the initial part of the OSL decay signal is basically the signal that is of interest for dating purposes when applying the SAR technique ( $\mathrm{Li}$ and $\mathrm{Li}, 2006)$. Routinely, the net OSL signal used for $D_{e}$ calculation is obtained by subtracting a mean background estimate by averaging photon counts in the late part of the decay curve from integration of the initial part of the curve. Thus, if a non-fast component appears in the initial part of the decay curve, the resulting $D_{e}$ value may be inaccurate. This can be verified by decomposing CW-OSL decay 
curves to a number of first-order exponential decaying components and investigating the relative proportion of each decaying component. The results of decay curve decomposition show that most natural decay curves decomposed into 2 to 3 components with the addition of a constant background if a Bayesian Information Criterion is applied (Peng et al., 2014).

Figure 3 shows the relative contribution of each decaying component in a natural decay curve of sample GL1-1, calculated using the decomp() function of the R package numOSL (Peng et al., 2013). The fast component contributed more than $80 \%$ to the total signal between 0 and $0.2 \mathrm{~s}$ and decayed rapidly after $0.2 \mathrm{~s}$. In contrast, the proportion of the medium component increased from $10 \%$ at $0.25 \mathrm{~s}$ to $35 \%$ at $1 \mathrm{~s}$. This indicated that only the first $0.2 \mathrm{~s}$ of the decay curve was dominated by the fast component, and that the contribution of the non-fast components must be taken into account after $0.2 \mathrm{~s}$. We used a $D_{e}(t)$ plot (Bailey, 2000) to detect the sensitivity of the $D_{e}$ determination to selection of the integration time interval (Fig. 4). $D_{e}$ values were calculated at successive intervals of $0.16 \mathrm{~s}$. The $D_{e}(t)$ plots of aliquots from the same sample showed different characteristics. Some indicated a decrease in $D_{e}$ values in only the first few intervals followed by large variation up and down when later intervals were used. Others showed a typical decrease in $D_{e}$ values towards the later part of the time intervals. Previous studies demonstrated that a thermally unstable non-fast decaying component may be responsible for the decline in $D_{e}$ values with successive time intervals ( $\mathrm{Li}$ and Li, 2006; Shen and Mauz, 2009; Steffen et al., 2009). That is because the thermally unstable non-fast component that eroded in the natural decay curve can be presented in subsequent artificial decay curves corresponding to test and regenerative doses. Consequently, the growth curve constructed by using sensitivity-corrected artificial OSL signals is too high compared to the sensitivity-corrected natural OSL signal, resulting in $D_{e}$ underestimation.

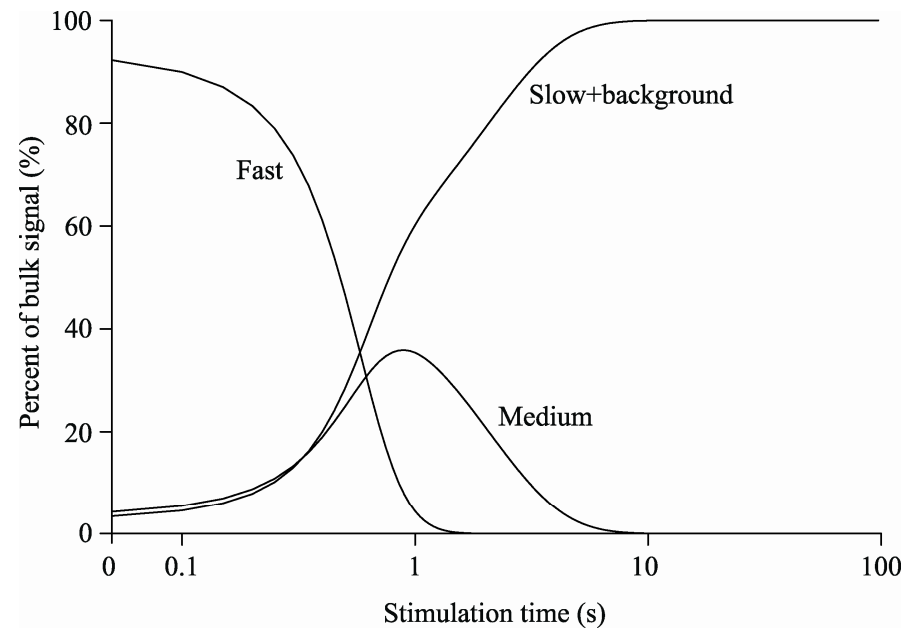

Fig. 3 Relative contributions of different decaying components from the natural OSL decay curve of an aliquot of sample GL1-1

Rather than subtracting an estimate of constant background from the late part of an OSL decay curve, Ballarini et al. (2007) found that more accurate $D_{e}$ values could be obtained if the constant background count is estimated from the part of an OSL decay curve immediately following the interval of the channels used for calculation of the net OSL signal. This was further validated by Cunningham and Wallinga (2010) as well as by other researchers who applied OSL dating to young sediments (Costas et al., 2012; Shen and Mauz, 2012).

By comparing the results of a component-resolved $D_{e}$ calculation, Peng and Han (2013) found that the manner in which selection of the integration time interval was done can strongly affect the accuracy of $D_{e}$ values for these samples. We therefore used two different integration intervals to calculate $D_{e}$ values and compare their reliability: (a) early background subtraction (EBS), for which the net OSL signal was obtained by integrating the OSL signal from the first $0.32 \mathrm{~s}$ and 
the background signal was estimated from the OSL signal between 0.32 and $1.12 \mathrm{~s}$; and (b) late background subtraction (LBS), for which the net OSL signal was calculated from the first $0.64 \mathrm{~s}$ of the OSL decay curve and the background signal was obtained from the OSL signal between 32 and $40 \mathrm{~s}$.
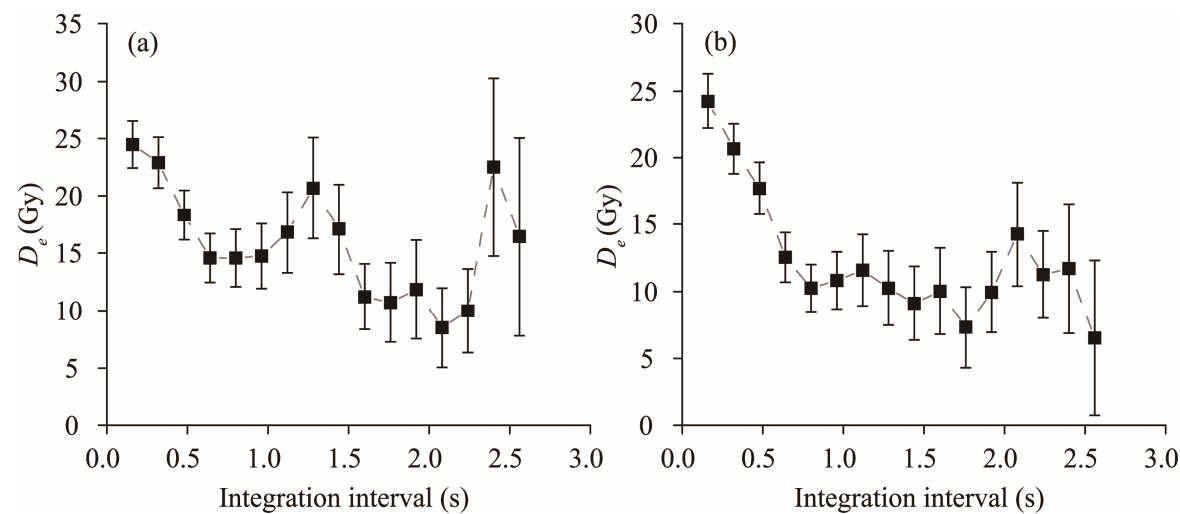

Fig. $4 D(t)$ plots showing $D_{e}$ values variations with equal-width successive interval selections for two different aliquots from sample GL1-1. Some aliquots exhibit an obvious decrease in $D_{e}$ values but only within the first $0.5 \mathrm{~s}$ (a), whereas other aliquots showed more typical decreases in $D_{e}$ values towards later intervals (b).

We carried out fast component $D_{e}$ estimations to assess the degree of quality of the $D_{e}$ estimates obtained using the EBS and LBS methods. To do so, we decomposed the decay curves from each aliquot of these samples obtained from the SAR sequence into two exponential components and one constant component, and the numbers of trapped electrons from the fast component were used to construct a fast component growth curve and calculate a fast component $D_{e}$ value for each aliquot (Peng et al., 2013). A total of 181 fast component $D_{e}$ values were obtained from these samples, and Fig. 5 compares the $D_{e}$ estimation from the EBS and LBS methods. We adopted a paired two-sided $t$-test with a significance level of $1 \%$ (Peng and Dong, 2014) to identify significance differences between the resulting $D_{e}$ estimates. We calculated $t=1.11$ for the difference in $D_{e}$ values between the fast component and EBS methods, and $t=6.64$ for the difference in $D_{e}$ values between the fast component and LBS methods. Because $t=2.60$ was the critical $t$-value in both cases, this implies that there was only a significant difference between the $D_{e}$ values obtained using the fast component and LBS methods and that $D_{e}$ values determined by the LBS method are clearly underestimated, particularly for older samples when $D_{e}$ values exceeded $30 \mathrm{~Gy}$. We still do not know whether the underestimate of $D_{e}$ values was caused by the unstable medium or by slow decaying components. Thus, further study is required.
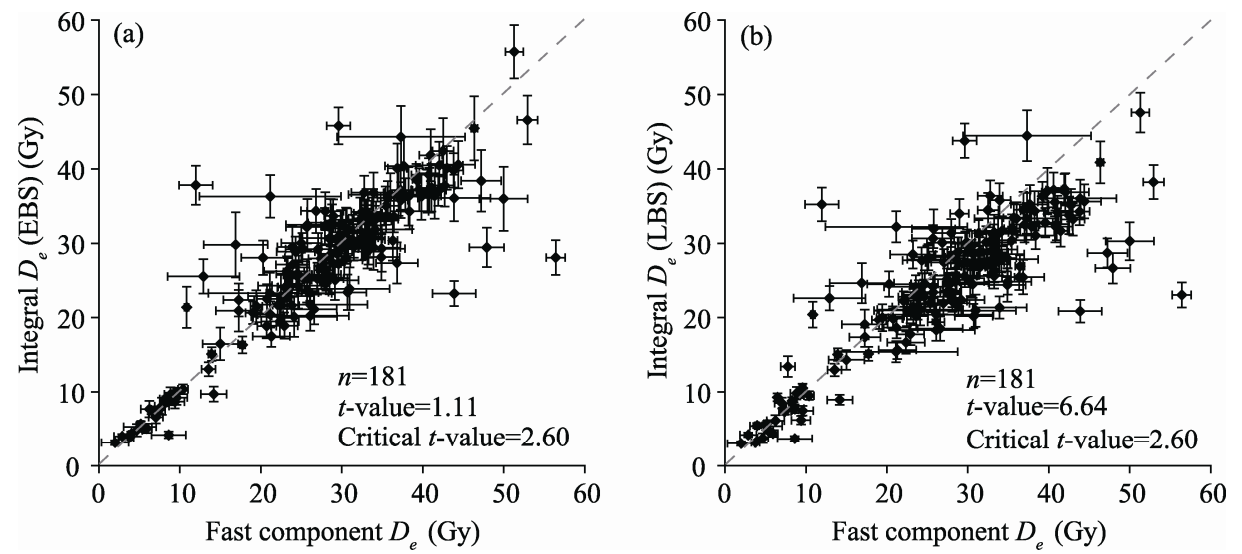

Fig. 5 Scatter plots of the fast component $D_{e}$ values estimated by decay curve decomposition versus the integral $D_{e}$ values obtained through bulk signal integration with (a) early background subtraction and (b) late background subtraction. Dashed lines indicate $y=x$. 


\subsection{Determining $D_{e}$ and calculating ages}

Although component-resolved $D_{e}$ calculations provide more reliable dose estimates, the standard errors are generally large (with relative standard errors ranging from $50 \%$ to $80 \%$ in some cases) compared to those obtained through bulk signal integration, as seen in Fig. 5. Given that differences between $D_{e}$ values obtained from the component-resolved and EBS methods were insignificant, as indicated by $t$-tests, we adopted the integrated OSL signal using EBS to calculate $D_{e}$ values for this study. Standard errors of the $D_{e}$ values were based on uncertainties in photon counting statistics and curve-fitting errors. We added an additional uncertainty of 5\% in quadrature to the relative standard errors of the measured $D_{e}$ values to account for sources of errors that were not considered, such as instrument reproducibility, over-dispersed variance of photon counts compared to an assumed Poisson distribution, and variability in measured dose distributions arising from other intrinsic factors, such as thermal transfer and non-homogenous laboratory beta source. We consider this to represent the minimum uncertainty for which a $D_{e}$ value can be calculated from an aliquot.

$D_{e}$ distributions for each of the studied samples are shown as radial plots in Fig. 6. $D_{e}$ values of these samples fell within reasonably narrow ranges and displayed homogeneous distributions. Partial bleaching is unlikely in an aeolian environment. Although disturbances after deposition are possible, we observed distinct cross-bedded sand layers caused by regular wind activity within the study area during our field investigation. This indicated that the sedimentary units had remained intact since deposition occurred, and that the effect of bioturbation was minimal. $D_{e}$ values for the samples were estimated using the central age model (Galbraith et al., 1999; Galbraith and Roberts, 2012) and are summarized in Table 1. This model was implemented using the RadialPlotter() function provided in the numOSL package of the $\mathrm{R}$ statistical software (Peng et al., 2013).

Table 1 A summary of the environmental radioactivity and OSL results for the samples

\begin{tabular}{cccccccc}
\hline Sample & $\mathrm{K}(\%)$ & $\mathrm{Th}\left(10^{-6}\right)$ & $\mathrm{U}\left(10^{-6}\right)$ & $\begin{array}{c}\text { Water content } \\
(\%)\end{array}$ & $\begin{array}{c}\text { Dose rate } \\
(\mathrm{Gy} / \mathrm{ka})\end{array}$ & $\begin{array}{c}\text { Equivalent dose } \\
(\mathrm{Gy})\end{array}$ & Age (ka) \\
\hline GL1-1 & $2.00 \pm 0.11$ & $8.63 \pm 0.34$ & $2.86 \pm 0.19$ & $5.0 \pm 5.0$ & $3.29 \pm 0.24$ & $25.04 \pm 0.68$ & $7.62 \pm 0.59$ \\
GL1-2 & $2.02 \pm 0.11$ & $8.27 \pm 0.34$ & $2.00 \pm 0.18$ & $3.0 \pm 5.0$ & $3.17 \pm 0.24$ & $7.33 \pm 0.55$ & $2.31 \pm 0.25$ \\
GL2-1 & $2.16 \pm 0.10$ & $8.39 \pm 0.32$ & $1.83 \pm 0.17$ & $2.0 \pm 5.0$ & $3.26 \pm 0.25$ & $34.51 \pm 0.84$ & $10.60 \pm 0.84$ \\
GL2-2 & $1.81 \pm 0.09$ & $6.90 \pm 0.27$ & $1.78 \pm 0.16$ & $2.0 \pm 5.0$ & $2.84 \pm 0.21$ & $32.65 \pm 0.91$ & $11.49 \pm 0.92$ \\
GL2-3 & $1.89 \pm 0.11$ & $10.90 \pm 0.37$ & $2.70 \pm 0.20$ & $7.0 \pm 5.0$ & $3.23 \pm 0.23$ & $30.55 \pm 0.98$ & $9.47 \pm 0.75$ \\
GL2-4 & $2.06 \pm 0.10$ & $10.30 \pm 0.34$ & $2.73 \pm 0.19$ & $6.0 \pm 5.0$ & $3.40 \pm 0.24$ & $32.17 \pm 1.18$ & $9.46 \pm 0.76$ \\
\hline
\end{tabular}

Note: Equivalent dose values for the samples were estimated using the central age model.

Radionuclide activity concentrations were measured through neutron activation analysis for the $\mathrm{U}$, Th, and $\mathrm{K}$ concentrations (Table 1) in bulk samples obtained from the China Institute of Atomic Energy in Beijing. We calculated the water contents from the sample weights before and after drying, and accounted for a 5\% uncertainty in water content in the dose rate calculations. The contribution of cosmic ray dose rate was estimated according to the method of Prescott and Hutton (1994). Table 1 and Fig. 7 summarize the resulting OSL ages.

\subsection{Regional aeolian activity revealed by OSL chronologies and the resultant palaeoclimatic implications}

Figure 7 summarizes the OSL ages and stratigraphic positions. Two aeolian sand samples (GL2-1 and GL2-2) yielded OSL ages of $10.60 \pm 0.84$ and $11.49 \pm 0.92 \mathrm{ka}$, respectively. It is worth noting that these two ages are considered unstratified if their measurement errors are not taken into account. Age inversions may simply arise from dating uncertainties or may imply that the sedimentary unit was accretional during a period of fast deposition. TL dating results from the bottom and top of an aeolian sand unit from the Xiangshan section (Qiang et al., 2000) obtained south of Zhongwei city provided ages of $19.12 \pm 1.40$ and $11.40 \pm 0.80 \mathrm{ka}$, respectively, and an OSL sample from the central part of this unit yielded an age of 12.19 $\pm 1.16 \mathrm{ka}$ (Qiang et 
al., 2010). Sedimentary rates from this deposit layer were estimated at 45.6 and $68.4 \mathrm{~cm} / \mathrm{ka}$, which were determined for the intervals from 19.12 to $12.19 \mathrm{ka}$ and from 12.19 to $11.14 \mathrm{ka}$, respectively (Qiang et al., 2010), reflecting fast expansion and accumulation of sand dunes

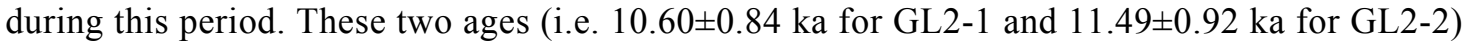
compared well with an OSL age of $11.09 \pm 0.66$ ka recorded in sedimentary section S202-25 (Fig. 1) south of Zhongwei city (Feng et al., 2013). A sand sample from the lower part of section S202-25 was OSL-dated at $15.24 \pm 1.02 \mathrm{ka}$. These OSL ages indicated that the dune field buildup and sand dune mobilization that occurred in the southern region of the Tengger Desert began from the Last Glacial Maximum. Evidences of sand dune buildup before $10 \mathrm{ka}$ has also been recorded by sedimentary records from adjacent dune fields at $12.06 \pm 0.56,10.46 \pm 0.51$, and $10.14 \pm 0.55 \mathrm{ka}$ in aeolian samples from the northern region of the Ulan Buh Desert, located in the northeastern Tengger Desert (Zhao et al., 2012). Chronological data from a number of dune fields (mainly from the Mu Us, Otindag, and Tengger deserts) based on extensive absolute dating reveals that aeolian sand was active at many sites along the desert margin in northern China between 11.5 and $8.0 \mathrm{ka}$ (Mason et al., 2009).
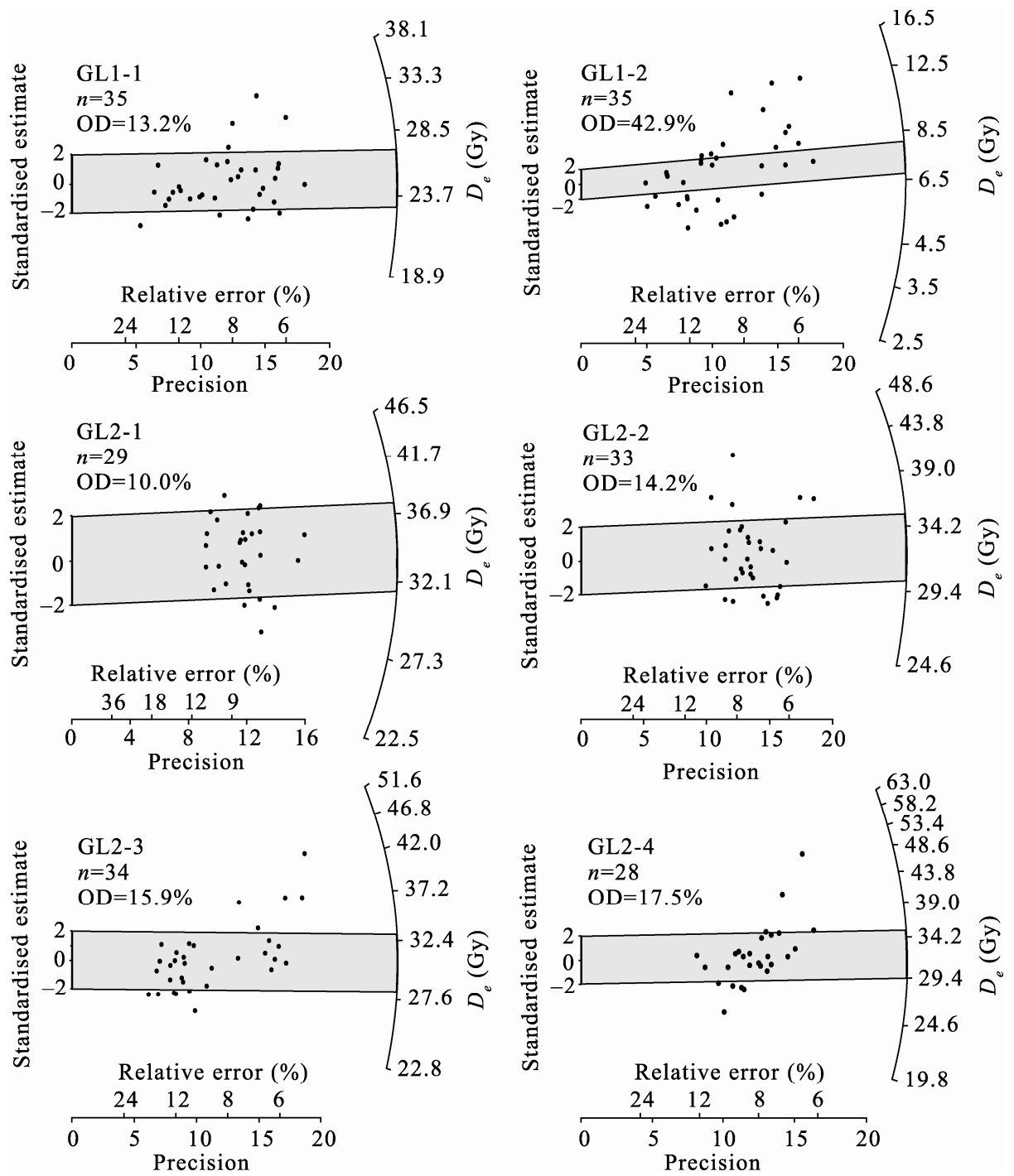

Fig. 6 Radial plots showing the $D_{e}$ distributions for the studied samples. The shadowed region in each plot is centered on the $D_{e}$ determined by the central age model (Galbraith et al., 1999; Galbraith and Roberts, 2012). $n$ indicates the number of aliquots in each distribution, and OD denotes the over-dispersion value of each dataset. 


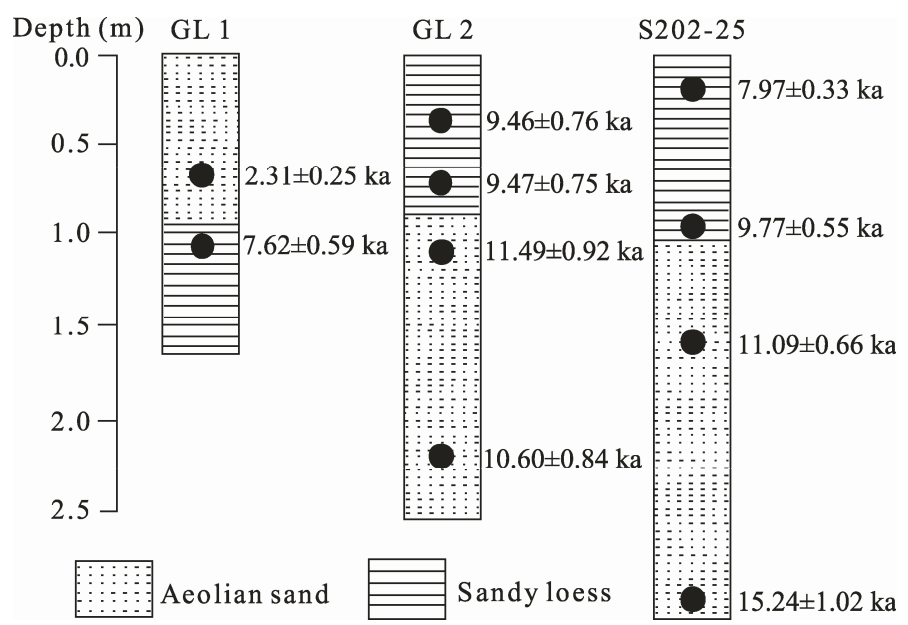

Fig. 7 Stratigraphy and optical ages of the two studied sedimentary sequences. Sequence S202-25 from the Xiangshan section in the south of the Zhongwei city (Feng et al., 2013) is shown here for comparison purpose.

Dune field expansion before $10 \mathrm{ka}$ suggests that this period experienced arid conditions with low effective moisture levels. Aeolian activity was also found between 12.4 and $11.5 \mathrm{ka}$ in the eastern Qaidam Basin (Yu and Lai, 2012) and between 11.8 and $11.0 \mathrm{ka}$ in the Gonghe Basin (Qiang et al., 2013) in the northeastern Qinghai-Tibetan Plateau, which lies southwest of our study area. This period generally coincides with the peak insolation period between 11.0 and 10.0 $\mathrm{ka}$ (Berger and Loutre, 1991). The intense summer insolation would have resulted in strong uplift of air masses and would have formed a low-pressure cell over the Tibetan Plateau (Long et al., 2010). This would have increased subsidence of air masses into lowland areas adjacent to the northern edge of the Tibetan Plateau and a subsequent decrease in moisture in the area (Broccoli and Manabe, 1992). Mason et al. (2009) inferred that the zone of subsidence linked to the Asian monsoon included not only the deserts north and northwest of the Tibetan Plateau, but also a band of dry land extending eastward across southern Mongolia and northern China. Furthermore, increased monsoonal precipitation caused by a stronger summer monsoon intensity during this period may have been offset by high levels of evaporation as a result of higher temperatures (Mason et al., 2009; Long et al., 2010). In consequence, effective moisture and vegetation cover may have decreased, resulting in enhanced mobilization of aeolian sand and expansion of dune fields.

Sandy loess sample GL2-3 and GL2-4 provided two indistinguishable OSL ages (i.e. 9.47 \pm 0.75 and $9.46 \pm 0.76 \mathrm{ka}$, respectively). This is consistent with an OSL age of $9.77 \pm 0.55 \mathrm{ka}$ from section S202-25 (Feng et al., 2013), indicating that sand dune stabilization accompanied by improved vegetation cover occurred after $\sim 9.5 \mathrm{ka}$. The sandy loess in sample GL1-1, with an OSL age of $7.62 \pm 0.59 \mathrm{ka}$, also coincided with an OSL age (i.e. $7.97 \pm 0.33 \mathrm{ka}$ ) obtained from the top of section S202-25, suggesting that sand dunes stabilized during this period. OSL dating has recently shown ages from the bottom and top of a paleosol layer from the Xiangshan section at $10.59 \pm 1.83$ and $7.21 \pm 0.55 \mathrm{ka}$, respectively (Qiang et al., 2010). An organic paleosol sample from the Baiyangou section at the southern margin of the Tengger Desert yielded a ${ }^{14} \mathrm{C}$ age of $8.56 \pm 0.046 \mathrm{ka} \mathrm{BP}$ (Li et al., 2006). The paleosol layer suggests a period of dune field stabilization that developed when fine-grained dust was trapped under vegetation. This indicates that a wetter climate prevailed in the southern Tengger Desert during this period. A comprehensive analysis of several hundred OSL ages from the late Quaternary reveals that desert areas in northwestern and north-central China decreased by $5 \%$ to $20 \%$ between 9.0 and $5.0 \mathrm{ka}$ (Lu et al., 2013).

OSL ages obtained in the present study suggest that a main phase of sand dune stabilization occurred between 9.5 and $7.6 \mathrm{ka}$. However, it should be noted that the time when dune stabilization ended cannot be definitively determined from the limited chronology presented here. This is due to insufficient sampling data. The balance between precipitation and evaporation 
controls effective moisture, which in turn plays a significant role in dune activity through its effects on vegetation cover (Mason et al., 2009). Although summer insolation has gradually decreased since $10 \mathrm{ka}$, lower temperatures resulted in lower evaporation and decreased subsidence of air masses in this region. This may have led to an increase in effective moisture levels. The transition from accumulating sand dune deposits before $\sim 10 \mathrm{ka}$ to the development of sandy soils between 9.5 and 7.6 ka suggests that if an effective moisture threshold is attained, aeolian activity will be largely restricted. Feng et al. (2013) estimated that the southern margin of the Tengger Desert may have retreated roughly $20 \mathrm{~km}$ to the north during this humid period. A review of published luminescence-dated sedimentary records from a number of desert sites indicates that sand dune stabilization was a general phenomenon in northern China from the early to middle Holocene. However, the timing of the commencement and termination of this dune stabilization period is asynchronous (Yang et al., 2010). This suggests that conditions of effective moisture during the early Holocene differed among the various dune fields in northern China.

Sample GL1-2, which was composed of aeolian sand deposits, yielded an OSL age of $2.31 \pm 0.25 \mathrm{ka}$. This could imply that sand dunes became mobilized again at some point during the last several thousand years in this region due to increased aridity. Sedimentary records and pollen data from the southern margin of the Badain Jaran Desert show that climate conditions became increasingly cool and dry after $2.5 \mathrm{ka}$ BP (Dong et al., 1995). Dune fields in northern China experienced relatively dry conditions after $2.4 \mathrm{ka} \mathrm{BP}$ (Lu et al., 2006). The single age presented in this work makes it impossible to reconstruct a detailed history of dune activity during the late Holocene. Therefore, further evidence is required to understand periods of aeolian activity during this time within the region.

Interpreting chronologies from aeolian sedimentary records is inherently difficult, since the sedimentary structures of dunes are discontinuous and stochastic processes during dune development may lead to gaps in certain chronological records while at the same time leading to thick sedimentary layers in other records (Leighton et al., 2014). The ages of sediments derived from OSL describe only a part of the sedimentation history, and sediment samples from as many locations as possible are needed to accurately determine their ages (Singhvi and Porat, 2008). Available chronological data depends heavily on both the sampling strategy and the dating precision (Leighton et al., 2014). Given that the chronologies of Holocene aeolian sand samples from the Tengger Desert in earlier studies were mainly based on radiocarbon dating and that only limited OSL-derived ages have been reported for this area until recently, future studies of dune chronology in this area should employ multiple-site, high-resolution sampling methods and advanced dating techniques such as OSL.

\section{Conclusions}

In this work, we dated Holocene sandy deposits from Gulang county at the southern margin of the Tengger Desert using OSL. Our results demonstrated that: (1) $D_{e}$ calculations were sensitive to the selected integration intervals, and certain aliquots showed a decrease in $D_{e}$ values with successively integration intervals. This may be attributable to the presence of thermally unstable non-fast components, and this phenomenon consequently requires further investigation. Employing an early background subtraction approach avoids the problem of $D_{e}$ underestimation. (2) The OSL ages indicated sand dune accumulation prior to $10 \mathrm{ka}$ due to intense insolation and low effective moisture levels. Sandy soil formed between 9.5 and $7.6 \mathrm{ka}$, when effective moisture levels increased. The transition from sand dune mobilization to stabilization implies that there is an effective moisture threshold that controls aeolian activity. The OSL-derived ages indicated that sand dunes were mobilized again at $\sim 2.3 \mathrm{ka}$ due to increased aridity. Further evidence is required to understand the history of aeolian activity during the late Holocene.

\section{Acknowledgements}

This study was funded by the National Basic Research Program of China (2013CB956000, 2012CB426501). Professor ZHAO Hui deserves a special mention for his involvement in discussions on the OSL ages and relevant palaeoclimatic implications. 


\section{References}

Bailey R M. 2000. The interpretation of quartz optically stimulated luminescence equivalent dose versus time plots. Radiation Measurements, 32(2): 129-140.

Ballarini M, Wallinga J, Wintle A G, et al. 2007. A modified SAR protocol for optical dating of individual grains from young quartz samples. Radiation Measurements, 42(3): 360-369.

Berger A, Loutre M F. 1991. Insolation values for the climate of the last 10 million years. Quaternary Science Reviews, 10(4): 297-317.

Broccoli A J, Manabe S. 1992. The effects of orography on midlatitude northern hemisphere dry climates. Journal of Climate, 5(11): 1181-1201.

Costas I, Reimann T, Tsukamoto S, et al. 2012. Comparison of OSL ages from young dune sediments with a high-resolution independent age model. Quaternary geochronology, 10: 16-23.

Cunningham A C, Wallinga J. 2010. Selection of integration time intervals for quartz OSL decay curves. Quaternary Geochronology, 5(6): 657-666.

Dong G R, Gao Q Z, Zou X Y, et al. 1995. Palaeoenvironmental evolution since the Late Pleistocene in the south margin of the Badain Jaran Desert. Chinese Science Bulletin, 40(13): 1214-1218. (in Chinese)

Feng H, Lu H Y, Yi S W, et al. 2013. The border changes of the deserts/sand field in the East Asian monsoon marginal region during the last Glacial maximum and Holocene optimum. Quaternary Sciences, 33(2): 252-259. (in Chinese)

Galbraith R F, Roberts R G, Laslett G M, et al. 1999. Optical dating of single and multiple grains of quartz from Jinmium rock shelter, northern Australia: Part I, experimental design and statistical models. Archaeometry, 41(2): 339-364.

Galbraith R F, Roberts R G. 2012. Statistical aspects of equivalent dose and error calculation and display in OSL dating: an overview and some recommendations. Quaternary Geochronology, 11: 1-27.

Gao S Y, Wang G Y, Ha S, et al. 2001. A case study on desert evolution in the northwestern fringe of monsoon area, China since the last glacial epoch. Quaternary Sciences, 21(1): 66-71. (in Chinese)

Lai Z P, Brückner H. 2008. Effects of feldspar contamination on equivalent dose and the shape of growth curve for OSL of silt-sized quartz extracted from Chinese loess. Geochronometria, 30(1): 49-53.

Leighton C L, Bailey R M, Thomas D S G. 2014. Interpreting and modelling late Quaternary dune accumulation in the southern Arabian Peninsula. Quaternary Science Reviews, 102: 1-13.

Li B, Li S H. 2006. Comparison of $\mathrm{D}_{\mathrm{e}}$ estimates using the fast component and the medium component of quartz OSL. Radiation Measurements, 41(2): 125-136.

Li Q, Pan B T, Gao H S, et al. 2006. Desert evolution and climate change of southern margin of Tengger desert since last glacial maximum. Journal of Desert Research, 26(6): 875-879. (in Chinese)

Li S H, Sun J M, Zhao H. 2002. Optical dating of dune sands in the northeastern deserts of China. Palaeogeography, Palaeoclimatology, Palaeoecology, 181(4): 419-429.

Li S H, Li B. 2006. Dose measurement using the fast component of LM-OSL signals from quartz. Radiation Measurements, 41(5): 534-541.

Li S H, Sun J M. 2006. Optical dating of Holocene dune sands from the Hulun Buir Desert, northeastern China. The Holocene, 16(3): 457-462.

Li S H, Chen Y Y, Li B, et al. 2007. OSL dating of sediments from deserts in northern China. Quaternary Geochronology, 2(1-4): 23-28.

Liu X J, Lai Z P, Yu L P, et al. 2012. Luminescence chronology of aeolian deposits from the Qinghai Lake area in the Northeastern Qinghai-Tibetan Plateau and its palaeoenvironmental implications. Quaternary Geochronology, 10: 37-43.

Long H, Lai Z P, Wang N A, et al. 2010. Holocene climate variations from Zhuyeze terminal lake records in East Asian monsoon margin in arid northern China. Quaternary Research, 74(1): 46-56.

Long H, Lai Z P, Fuchs M, et al. 2012. Palaeodunes intercalated in loess strata from the western Chinese Loess Plateau: Timing and palaeoclimatic implications. Quaternary International, 263: 37-45.

Lu H Y, Zhou Y L, Mason J, et al. 2006. Late quaternary climatic changes in northern China-new evidences from sand dune and loess records based on optically stimulated luminescence dating. Quaternary Sciences, 26(6): 888-894. (in Chinese)

Lu H Y, Yi S W, Xu Z W, et al. 2013. Chinese deserts and sand fields in Last Glacial Maximum and Holocene Optimum. Chinese Science Bulletin, 58(23): 2775-2783.

Lv P, Dong Z B, Zhang Z C, et al. 2009. Characteristics of wind velocity, temperature and humidity profiles of near-surface layer in Tengger desert. Journal of Desert Research, 29(5): 977-981. (in Chinese)

Mason J A, Lu H, Zhou Y, et al. 2009. Dune mobility and aridity at the desert margin of northern China at a time of peak 
monsoon strength. Geology, 37(10): 947-950.

Murray A S, Wintle A G. 2000. Luminescence dating of quartz using an improved single-aliquot regenerative-dose protocol. Radiation Measurements, 32(1): 57-73.

Pachur H J, Wünnemann B, Zhang H C. 1995. Lake evolution in the Tengger Desert, Northwestern China, during the last 40,000 years. Quaternary Research, 44(2): 171-180.

Peng J, Dong Z B, Han F Q, et al. 2013. R package numOSL: numeric routines for optically stimulated luminescence dating. Ancient TL, 31(2): 41-48.

Peng J, Han F Q. 2013. Selections of fast-component OSL signal using sediments from the south edge of Tengger Desert. Acta Geoscientica Sinica, 34(6): 757-762. (in Chinese)

Peng J, Dong Z B. 2014. A simple Bayesian method for assessing the standard error of equivalent dose estimates. Ancient TL, 32(2): 17-23.

Peng J, Dong Z B, Han F Q, et al. 2014. Estimating the number of components in an OSL decay curve using the Bayesian Information Criterion. Geochronometria, 41(4): 334-341.

Prescott J R, Hutton J T. 1994. Cosmic ray contributions to dose rates for luminescence and ESR dating: large depths and long-term time variations. Radiation Measurements, 23(2-3): 497-500.

Qiang M R, Li S, Jin M, et al. 2000. Aeolian deposits on the southeastern margin of Tengger desert and desert evolution during the last 60000 years. Journal of Desert Research, 20(3): 256-259. (in Chinese)

Qiang M R, Chen F H, Wang Z T, et al. 2010. Aeolian deposits at the southeastern margin of the Tengger Desert (China): Implications for surface wind strength in the Asian dust source area over the past 20,000 years. Palaeogeography, Palaeoclimatology, Palaeoecology, 286(1-2): 66-80.

Qiang M R, Chen F H, Song L, et al. 2013. Late Quaternary aeolian activity in Gonghe Basin, northeastern Qinghai-Tibetan Plateau, China. Quaternary Research, 79(3): 403-412.

Shen Z X, Mauz B. 2009. $D_{e}$ determination of quartz samples showing falling $D_{e}(t)$ plots. Radiation Measurements, 44(5-6): $566-570$.

Shen Z X, Mauz B. 2012. Optical dating of young deltaic deposits on a decadal time scale. Quaternary Geochronology, 10: $110-116$

Singhvi A K, Porat N. 2008. Impact of luminescence dating on geomorphological and palaeoclimate research in drylands. Boreas, 37(4): 536-558.

Steffen D, Preusser F, Schlunegger F. 2009. OSL quartz age under-estimation due to unstable signal components. Quaternary Geochronology, 4(5): 353-362.

Sun J M, Li S H, Han P, et al. 2006. Holocene environmental changes in the central Inner Mongolia, based on single-aliquot-quartz optical dating and multi-proxy study of dune sands. Palaeogeography, Palaeoclimatology, Palaeoecology, 233(1-2): 51-62.

Sun X, Lu H, Yi S, et al. 2013. Age and paleoenvironment of Paleolithic stone artifact remains discovered in the Tengger Desert, northern China. Journal of Arid Environments, 91: 129-137.

Yang L H, Zhou J, Lai Z P, et al. 2010. Lateglacial and Holocene dune evolution in the Horqin dunefield of northeastern China based on luminescence dating. Palaeogeography, Palaeoclimatology, Palaeoecology, 296(1-2): 44-51.

Yu L P, Lai Z P. 2012. OSL chronology and palaeoclimatic implications of aeolian sediments in the eastern Qaidam Basin of the northeastern Qinghai-Tibetan Plateau. Palaeogeography, Palaeoclimatology, Palaeoecology, 337-338: 120-129.

Zhao H, Li G Q, Sheng Y W, et al. 2012. Early-middle Holocene lake-desert evolution in northern Ulan Buh Desert, China. Palaeogeography, Palaeoclimatology, Palaeoecology, 331-332: 31-38. 